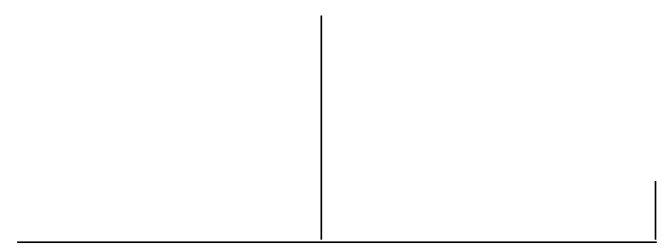

Rev. Latinoam. Psicopat. Fund., VI, 4, 23-38

\title{
Luto, tabu e ambivalência afetiva: a experiência de sofrimento no psíquico e na cultura*
}

\author{
Ana Karenina de Arraes Amorim \\ Terezinha de Camargo Viana
}

Este artigo aborda o tema da experiência de sofrimento no luto, tomando como referência algumas das construções teóricas de Sigmund Freud. Propõe-se a investigar as elaborações freudianas que concebem o luto como fenômeno psicológico que participa das tradições tabus, caracterizando-as e refletindo atitudes humanas diante da morte. A análise de tais tradições permite considerar que a ambivalência afetiva participa da experiência de sofrimento individual e das manifestações culturalmente compartilhadas de luto, de tal modo que contribui para a realização do "trabalho de luto" nas dimensões intrapsíquica e cultural.

Palavras-chave: Luto, tabu, ambivalência afetiva, cultura

* Este trabalho tem origem em "Cenários do luto: um estudo de elaborações freudianas" - dissertação de mestrado realizada na Universidade de Brasília sob a orientação da Prof ${ }^{a}$ Terezinha de Camargo Viana e defendida em dezembro de 2000 - e é uma versão ampliada do trabalho de mesmo título apresentado na mesa Psicanálise e Cultura, no VI Congresso Brasileiro de Psicopatologia Fundamental, realizado em setembro de 2002 na cidade do Recife, PE. 
Os objetos culturais atravessam o tempo e permitem que se dialogue com os seres humanos de outras épocas para o contínuo relacionar-se com os mistérios da vida e da morte.

Gilberto Safra (1999)

No presente trabalho buscamos compreender a concepção freudiana de luto tal como a percebemos desenvolvida sub-repticiamente às questões acerca das relações entre neurose e os elementos culturais primitivos referentes ao tabu, tendo por base a análise do texto "Totem e tabu" (1913). Para tanto, partimos do pressuposto de que o luto se insere como fenômeno que participa das tradições tabus e as caracteriza. A análise dessas tradições, e mais especificamente do tabu em relação aos mortos, permitiu que Freud formulasse a hipótese de que a ambivalência afetiva constitui um importante elemento na compreensão das relações afetivas nos primórdios da civilização, bem como das neuroses. Veremos, então, como a ambivalência afetiva participa da experiência e das manifestações de luto sob a forma de medo e temor aos mortos, os quais se convertem em demônios e em deuses a serem reverenciados. No sentido de pensar tais hipóteses recorremos às elaborações realizadas em outros momentos da teorização freudiana, tais como algumas das idéias desenvolvidas em "Mal-estar na civilização" (1930). Desse modo, parece possível lançar alguma luz sobre a dinâmica das relações afetivas humanas diante da realidade de morte no estudo de questões culturais.

\section{Sobre a definição de tabu: uma introdução}

Inicialmente, parece-nos importante realizar uma busca sobre a definição de tabu, tal como Freud empreende em "Totem e tabu" (1913), de modo a permitir uma compreensão mais clara dos elementos que serão discutidos em relação ao fenômeno do luto. 


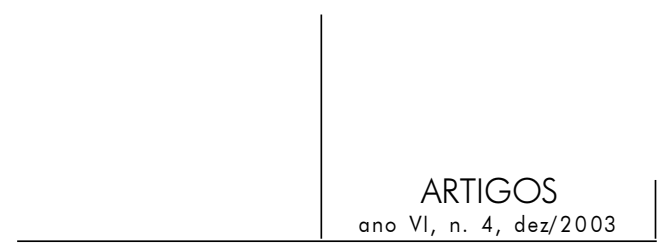

A palavra tabu é um termo polinésio cujo significado diverge em dois sentidos contrários. Se por um lado significa "sagrado, consagrado", por outro significa "misterioso, perigoso, proibido, impuro". Assim, a palavra "tabu" traz em si o sentido de algo inacessível, expresso por proibições e restrições. Entretanto, tais restrições não estão baseadas ou ligadas a nenhuma ordem divina (religiosa ou moral), sendo diferentes das proibições religiosas. São restrições que se impõem por conta própria, não têm fundamento e são de origem desconhecida, mas são tidas como coisa natural por aqueles que as sofrem, os quais estão convencidos de que qualquer violação terá severa punição.

Além disso, os tabus podem ser compreendidos em termos do seu objetivo essencial de proteger os indivíduos a ele submetidos e da sua fonte que é atribuída, segundo Freud (1913), ao poder mágico e perigoso que é inerente a pessoas ou espíritos, estando ligado a indivíduos especiais (reis, sacerdotes, recém-nascidos etc.), a situações especiais (menstruação, nascimento etc.) e a coisas misteriosas que têm poder de infecção e contágio (morte e doença). Esses tabus transmitem tal poder a outros por intermédio de objetos inanimados quando há transgressões das proibições. É interessante observar que tais proibições dirigem-se, principalmente, contra a liberdade de prazer e contra a liberdade de movimento e comunicação e visam abstinências e renúncias. Temos, então, que tabu denota tudo o que é veículo ou fonte desse misterioso atributo cuja forma é cindida em sagrado e impuro, exigindo e despertando, a um só tempo, veneração e horror.

É interessante também destacar a hipótese de Freud segundo a qual tais proibições coincidem com os mais antigos e poderosos desejos humanos de origem inconsciente, tal como revela a pesquisa psicanalítica, deixando reduzida a tese dele a uma única unidade, a saber: "A base do tabu é uma ação proibida para cuja realização existe forte inclinação inconsciente" (1913, p. 52).

Dessa forma, chegamos a uma síntese da definição de tabu, tal como Freud a propõe:

Tabu é uma proibição primeva forçosamente imposta (por alguma autoridade) de fora, e dirigida contra os anseios mais poderosos a que estão sujeitos os seres humanos. O desejo de violá-lo persiste no inconsciente; aqueles que obedecem ao tabu têm uma atitude ambivalente quanto ao que o tabu pró́be. O poder mágico atribuído ao tabu baseia-se na capacidade de provocar a tentação e atua como um contágio porque os exemplos são contagiosos e porque o desejo proibido no inconsciente desloca-se de uma coisa para outra. $\mathrm{O}$ fato de a violação de um tabu poder ser expiada por uma renúncia mostra que esta renúncia se acha na base da obediência ao tabu. (1913, p. 55) 


\section{Tabu relativo aos mortos}

Com base na definição de tabu, Freud analisa o comportamento humano frente à morte. Assim, observa que mesmo para os povos ditos primitivos, a morte de um homem, mesmo que seja um inimigo, é acompanhada de certas restrições ou observâncias "que estão incluídas entre as práticas do tabu. Essas observâncias podem ser distribuídas facilmente em quatro grupos. Elas exigem: 1) o apaziguamento do inimigo assassinado; 2) restrições sobre o assassino; 3 ) atos de expiação e purificação por parte dele; e 4) certas observâncias cerimoniais" (Freud, 1913, p. 56-7).

Freud vai apontando para as características cerimoniais que acompanham o assassinato do inimigo, visam o seu apaziguamento e suplicam pelo seu perdão, para que o espírito do morto não perturbe aqueles da tribo do assassino. Considerando tais práticas de apaziguamento do morto, podemos lembrar que dizem respeito a reações frente ao ato de matar e à morte de alguém, mesmo que esse alguém seja um inimigo. Assim, podemos supor que a morte de um inimigo toma o lugar de algo que é, ao mesmo tempo, sagrado e impuro, ou seja, o lugar de um tabu. E dentre as práticas tabus, destacamos as manifestações de luto dos assassinos em reverência ao seu inimigo morto, descritas nos seguintes termos:

Quando um índio pima matava um apache, tinha de passar por severas cerimônias de purificação e expiação. Durante um jejum de 16 dias não podia tocar em carne nem em sal, olhar para um fogo a arder ou falar com um ser humano. Morava sozinho na mata, assistido por uma velha, que lhe trazia sua escassa ração de comida. Banhava-se frequientemente no rio e (em sinal de luto) mantinha a cabeça coberta por um emplastro de lama. No décimo-sétimo dia havia uma cerimônia pública de purificação solene do homem e de suas armas. (ibid., p. 60)

Observamos, assim, que o inimigo é tratado como objeto de afeição pelos assassinos, para os quais o luto assume uma face ritualizada e que diz respeito a um estado quase que imposto, até mesmo obrigatório, que envolve lamentações, prantos e severas restrições. As manifestações de luto colocam-se como algo necessário, não só para o apaziguamento do morto, mas também para a expiação da culpa e purificação do assassino. Mas de onde viria essa obrigatoriedade do luto? Por que enlutar, com tantas observâncias e restrições, por um inimigo? O luto não supõe uma relação afetiva com o morto, como é comum que pensemos? Como fundamento de tais ritos de luto, parece haver um temor supersticioso em relação aos mortos cuja explicação talvez esteja na ambivalência afetiva como fundamento para tais ritos de apaziguamento do morto que compõem o luto, tal como defendida por Freud ao dizer: 


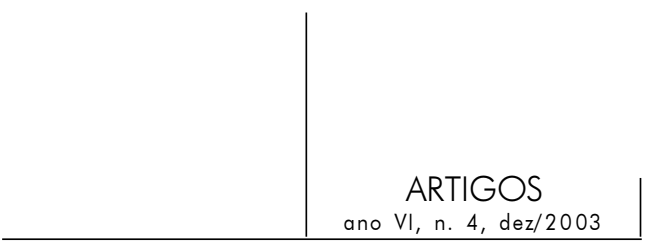

$\mathrm{Na}$ explicação aceita de todas estas observâncias de apaziguamento, restrição, expiação e purificação, dois princípios se combinam: a extensão do tabu do homem morto a tudo o que tenha entrado em contato com ele e o medo do seu fantasma. (...) podemos chamar a atenção para a unidade de nosso ponto de vista, que atribui a origem de todas essas observâncias à ambivalência emocional para com o inimigo. (ibid., p. 61)

A origem dessa "unidade de ponto de vista" voltada para a ambivalência emocional parece estar na compreensão de que tais observâncias, em relação ao morto e ao medo do seu fantasma, não são apenas manifestações de hostilidade. Parecem, antes, refletir o "mandamento vivo" do "não matarás". É como se o assassinato do inimigo evocasse não só os sentimentos hostis, mas também toda aquela ordem de afetos que participam dos ideais da cultura e que exigem dela certas leis.

Lembramos que em "Mal-estar na civilização" (1930) são desenvolvidas elaborações importantes acerca da organização social humana sob o comando de Eros, que empreende uma luta frente às expressões humanas de agressividade dirigida ao outro. Agressividade que contraria os desígnios eróticos de união dos seres em comunidade numa luta que se estabelece com o emprego de certos preceitos ou leis da cultura para controlar tais tendências agressivas. Dessa forma, parece que há aqui nessas referências sobre o luto vivido pelos inimigos em "Totem e tabu" (1913) uma semente das elaborações posteriormente desenvolvidas em Mal-estar na civilização sobre o controle da agressividade quando Freud afirma:

... o homem não é uma criatura terna e necessitada de amor, que só ousaria defender-se se lhe atacassem, senão, ao contrário, é um ser entre cujas disposições instintivas (pulsionais) também deve incluir-se uma boa porção de agressividade. Conseqüentemente, o próximo não representa unicamente um possível colaborador e objeto sexual, senão também um motivo de tentação para satisfazer nele sua agressividade (...) A existência de tais tendências agressivas, que podemos perceber em nós mesmos e cuja existência supomos com toda razão no próximo, é o fator que perturba nossa relação com os semelhantes, impondo à cultura tal emprego de preceitos. (Freud, 1930, p. 3.046)

As tendências agressivas que se revelam no tratamento relativo aos inimigos mortos são, pois, controladas pela cultura com a finalidade de manter as relações entre os homens. E isso parece valer também para o tratamento que é dispensado aos mortos de uma maneira geral:

Sabemos que os mortos são poderosos soberanos, mas talvez fiquemos surpresos de saber que podem ser tratados como inimigos. (...) O tabu sobre os mortos é - voltando à analogia da infecção - especialmente virulento entre a 


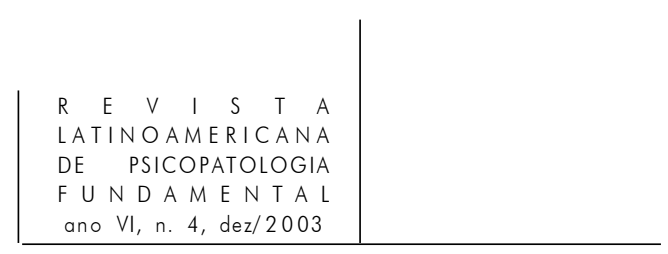

maioria dos povos primitivos. Manifesta-se, em primeiro lugar, nas conseqüências decorrentes do contato com os mortos e no tratamento dos que os pranteiam. (Freud, 1913, p. 72)

Aqui, o sentido do tabu em relação aos mortos coloca-os como inimigos, mesmo que em vida fossem os entes mais amados. É como se a morte igualasse inimigos e amigos ao atribuir-lhes o lugar de tabu; tabu esse que inclui tanto as observâncias, como o temor e medo dos mortos. Assim, um outro componente desse tabu se refere ao contato com os mortos, segundo o qual qualquer pessoa que tivesse manuseado o cadáver ou participado do enterro ficaria no mais alto grau de impureza, não podendo ter contato com os semelhantes ou mesmo com a comida com que se alimentaria, passando por um longo período de reclusão. O tabu em relação aos mortos segue também um grau de proibição que varia de acordo com o poder do morto e da pessoa a quem o tabu é imposto. Quanto mais poder tiver o morto, mais tempo é a impureza daquele que entrou em contato com o seu cadáver. Do mesmo modo, quanto mais poderoso é aquele que entrou em contato com o morto, menos tempo fica impuro.

Interessa-nos aqui, de modo mais específico, o tratamento que é dado às pessoas enlutadas - aos parentes ou pessoas mais próximos física e afetivamente do morto - que se caracteriza pelas mesmas proibições aplicadas àqueles que tiveram contato com o cadáver:

Em essência, as mesmas proibições (embora, de nosso ponto de vista, sejam mais interessantes) aplicam-se àqueles que estiveram em contato com os mortos apenas no sentido metafórico; os parentes enlutados da pessoa morta, viúvos e viúvas. As observâncias que até aqui mencionamos podem parecer dar simplesmente uma expressão característica à virulência do tabu e seu poder de contágio. Mas as que se seguem nos dão uma pista para as razões do tabu tanto as ostensivas quanto as que devemos encarar como as verdadeiras razões profundas subjacentes. (ibid., p. 74)

Com essa observação, Freud nos mostra que o estudo do tabu em relação aos enlutados nos aponta um outro caminho para o entendimento do tabu em relação aos mortos que vai, progressivamente, sendo construído. É interessante observar que o contato "metafórico" com o morto tem o mesmo valor ou a mesma qualidade de impureza que o contato físico, tal como anteriormente descrito. Esse contato tido como "metafórico" poderia ser entendido no sentido do contato ou ligação afetiva que mantém os enlutados ligados ao morto. Entretanto, a relação parece se estabelecer na ordem do corpo, como fica evidente nas seguintes observações:

Entre os shuswap da Colúmbia Britânica, as viúvas e viúvos enlutados são isolados e proibidos de tocar na própria cabeça e no próprio corpo; as canecas 


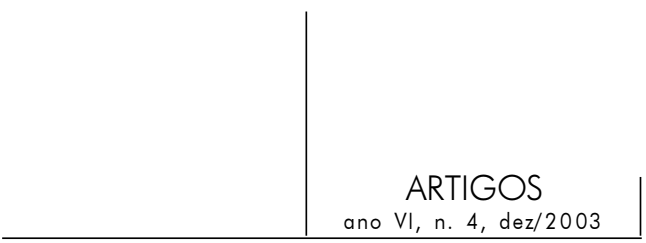

e panelas que utilizam não podem ser usadas por ninguém mais (...). Nenhum caçador chega perto dessas pessoas enlutadas porque a presença delas dá azar. (...) O mesmo propósito é mostrado ainda mais claramente no costume observado em outra tribo norte-americana, que estabelece que, após a morte do marido, "a viúva use por vários dias uma tanga feita de capim seco, a fim de impedir que o fantasma do marido tenha relações sexuais com ela". Isto sugere que o contato "num sentido metafórico" é, em última análise, entendido como sendo contato corporal porque o espírito do morto não abandona os seus parentes e não deixa de "pairar" sobre estes durante o tempo do luto. (ibid., p. 74)

O "contato metafórico", tal como apresentado, é entendido como corporal já que não se opõe à idéia de uma certa influência física (material) sobre os seus parentes enlutados. Ao manter uma relação no sentido espiritual com os seus parentes, é como se o espírito do morto ainda estivesse, por assim dizer, encarnado numa relação física (material) poderosa com eles. Percebemos, também, que as práticas tabus em questão dirigem-se especialmente aos viúvos e viúvas que parecem estar submetidos ao "perigo da tentação de manter relações sexuais" com outros substitutos do morto e, como já visto, com o próprio morto. Haveria, então, um elemento que remete à repressão do desejo sexual ou restrições sexuais, tanto para o homem como para a mulher. Além disso, a mulher enlutada parece colocada numa posição especial de tentação na medida em que desperta o desejo de outros homens por estar "sem amo e senhor". É como se o luto figurasse uma situação em que a repressão sexual atua de uma maneira mais intensa pelo próprio "perigo" que o enlutado representa, estando livre sexualmente para procurar novos objetos de satisfação. As restrições a que são submetidos os enlutados também constituem uma expressão do "controle" das tendências sexuais à semelhança das tendências agressivas. Nesse caso, temos também que os costumes ligados ao luto apontam para as restrições e proibições que a cultura impõe à sexualidade.

Sob outro aspecto, as observâncias dos tabus em relação aos mortos, do mesmo modo que os sintomas neuróticos, têm um duplo sentido no que se refere às restrições sexuais a que os enlutados ficam submetidos:

Por um lado, em seu caráter restritivo, são expressões de pesar, mas, por outro, traem claramente a coisa que procuram ocultar - uma hostilidade contra o morto disfarçada de autodefesa. Já sabemos que certos tabus surgem do medo da tentação. $O$ fato de um homem morto achar-se em desamparo está fadado a atuar como um incentivo a que o sobrevivente dê rédea livre às suas paixões hostis e essa tentação tem de ser contradita por uma punição. (ibid.6, p. 83)

Mais uma vez a questão da hostilidade, agora aliada às tendências sexuais, aparece na explicação freudiana relativa às observâncias a que os enlutados estão submetidos. 


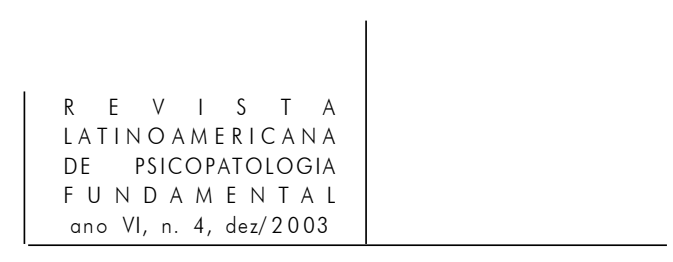

Temos, portanto, que o luto vai se revelando nas elaborações freudianas, aqui analisadas, como uma manifestação cultural na medida em que dele também participam os aspectos restritivos ou controladores das tendências agressivas (hostilidade) e sexuais que são impostas pela cultura com a finalidade de manter seus membros unidos em comunidade mediante o estabelecimento de vínculos libidinais coartados, ou seja, vínculos libidinais que estão submetidos a essas restrições.

Talvez o sentido dessas práticas culturais, assim como do processo de luto vivido nessas práticas, possa ser esclarecido a partir de dois elementos ou peculiaridades importantes no tabu, a saber: o medo e a reverência aos mortos.

\section{Os mortos como demônios e deuses: medo e reverência no luto}

$\mathrm{Na}$ análise das elaborações de Freud sobre o luto e o tabu em relação aos mortos, deparamo-nos ainda com a preocupação de que algum lugar deve ser atribuído à tristeza pela morte, junto ao horror relativo ao morto como componente do luto. Entretanto, como vimos, o horror não explica todas as observâncias de tabus que foram descritas, nem mesmo o sofrimento. Ao contrário, o sofrimento tende a levar o enlutado a preocupar-se com o morto, a prolongar sua lembrança e preservá-la tanto quanto possível. Assim, Freud postula que algo mais explica as peculiaridades das práticas tabus em relação aos mortos: o medo dos mortos. Tal componente psicológico do tabu se coloca na medida em que os enlutados admitem terem medo da presença ou do retorno dos mortos como se eles se tornassem demônios:

Esta teoria baseia-se numa suposição tão extraordinária que à primeira vista parece inacreditável, ou seja, a suposição de que um parente ternamente amado, no momento de sua morte, transforme-se num demônio, de quem os sobreviventes nada podem esperar a não ser hostilidade e contra cujos desejos perversos devem proteger-se por todos os meios possíveis. (Freud, 1913, p. 79-80)

Coloca-se, então, como um desafio entender a origem e o sentido desse medo dos mortos. Como alguém amado passa a ser temido como um demônio? Por que se transformaram em demônios? A análise das contribuições freudianas aponta para a idéia de que nesses povos (e talvez também nos dias de hoje, sob outras formas) o medo dos mortos, o medo de que os espíritos dos mortos retornem e perturbem os vivos, como se fossem verdadeiros demônios, está associado ao medo da morte que parece residir muito intimamente em cada ser 


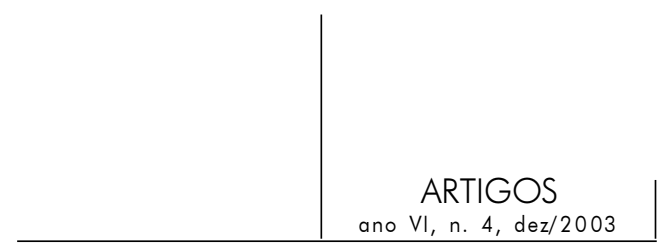

humano. ${ }^{1}$ Assim sendo, poderíamos pensar que o medo da morte seria a razão última de todas as práticas tabu relacionadas aos mortos e que acompanham o luto?

Para entender tais razões sobre a existência destas práticas tabus, Freud sugere outro caminho a partir do estudo das psiconeuroses. Nesse sentido, apresenta algumas elaborações sobre as auto-acusações que se desenvolvem no período de luto e que se relacionam com as práticas tabus, introduzindo algumas das questões que foram posteriormente trabalhadas no artigo "Luto e melancolia" (1917). Para ele, algumas pessoas empreendem auto-acusações sob a forma de fortes dúvidas sobre as suas responsabilidades (culpa) pela morte do ente querido.

Nesse ponto, chamamos atenção para a hipótese de que essas autoacusações são motivadas pela hostilidade inconsciente do enlutado dirigida ao morto, revelando a ambivalência dos afetos em relação a ele e que as justificaria:

Descobrimos que, num certo sentido, essas auto-acusações objetivas são justificadas, e é esta a razão de constituírem prova contra contradições e protestos. Não é que a pessoa enlutada seja realmente responsável pela morte ou na realidade culpada de negligência, como as auto-acusações declaram ser o caso. Não obstante, havia algo nela - desejo que lhe era inconsciente - que não ficaria insatisfeito com a ocorrência da morte e que poderia realmente tê-la ocasionado, se tivesse poder para isso. E após a morte haver ocorrido, é contra esse desejo inconsciente que as censuras são uma reação. Em quase todos os casos em que existe uma intensa ligação emocional com uma pessoa em particular, descobrimos que por trás do terno amor há uma hostilidade oculta no inconsciente. Esse é o exemplo clássico, o protótipo, da ambivalência das emoções humanas. (Freud, 1913, p. 82)

Entendemos a ambivalência emocional, teorizada a partir da análise de neuróticos obsessivos e do estudo das práticas tabus, como elemento importante na compreensão freudiana da atitude humana diante da morte e do próprio luto. Um outro elemento explicativo do tabu e do medo relativo aos mortos, proposto por Freud, seria a idéia de projeção:

1. Fustel de Coulanges (1998) corrobora aqui nossas observações ao informar que os gregos chamavam as almas humanas divinizadas pela morte de demônios ou heróis. E acrescenta: "É possível que o sentido primitivo da palavra hêrôs fosse o de homem morto. A linguagem das inscrições, exprimindo-se na fala do vulgo e sendo, simultaneamente, aquela em que o sentido da palavra persiste por mais tempo, emprega algumas vezes hêrôs com a significação natural que nós damos à palavra defunto (...) Os gregos davam também à alma do morto o nome de daímôn.” (p. 453) 


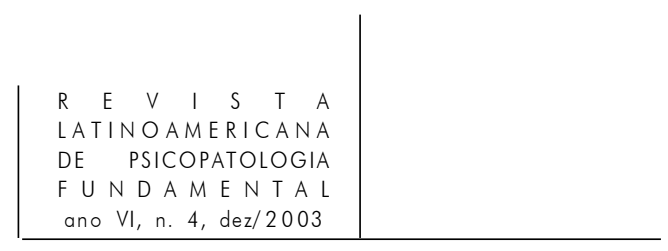

Descobrimos agora um motivo que pode explicar a idéia de que as almas dos que morreram são transformadas em demônios e a necessidade sentida pelos sobreviventes de proteger-se de sua hostilidade através de tabus. (...) A defesa contra ela assume a forma de deslocá-la para o objeto da hostilidade, ou seja, para os próprios mortos. Esse procedimento defensivo, comum tanto na vida mental normal quanto na patológica, é conhecido como "projeção". O sobrevivente nega, assim, que tenha algum dia alimentado quaisquer sentimentos hostis contra o morto querido; em vez disso, é a alma do defunto que os alimenta e procura colocá-los em ação durante todo o período de luto. (ibid., p. 82-3)

O mecanismo da projeção, ${ }^{2}$ assim utilizado defensivamente contra a própria hostilidade inconsciente, pode constituir um procedimento da vida mental que coloca em ação - numa possível ação dos mortos sobre os vivos - a hostilidade destes. Nesse sentido, o tabu em relação aos mortos surge, como os outros, do contraste existente entre o sofrimento consciente e a satisfação inconsciente pela morte que ocorreu. Esse tabu será tão mais intenso quanto o é a ligação afetiva com o morto. É interessante observar também que, apesar de aproximar a compreensão das autocensuras obsessivas e das práticas tabu, Freud evidencia a diferença que separa, no tempo e na história humana, as duas formas de lidar com a morte. Se os povos ditos primitivos projetam sua hostilidade dirigida aos entes queridos para os mortos, os neuróticos dirigem para o próprio eu tal hostilidade que se converte em autocensuras obsessivas.

Diante da ambivalência emocional que se revela e atua por ocasião do luto, o mecanismo da projeção funciona como uma espécie de solução apaziguadora do conflito entre esses sentimentos contrários (ódio e amor) em relação ao morto. A hostilidade inconsciente é, por meio da projeção, deslocada para a realidade material e para o outro que assume a forma de demônio, do mesmo modo que é devolvida à realidade psíquica, mais precisamente ao eu, sob a forma de atitudes autodepreciativas dos neuróticos e melancólicos.

Mas, se é assim, o que acontece nesse momento de luto para que a hostilidade se torne tão evidente de tal forma que têm lugar práticas tabus e autocensuras obsessivas? Com essa questão em mente, encontramos nas palavras de Freud uma espécie de síntese sobre o papel da hostilidade latente que, por ocasião do luto, passa a ser manifesta:

O momento da morte (...) parece certamente uma ocasião muito inapropriada para a recordação de qualquer motivo justificável que possa existir para queixas.

2. O termo projeção tal como aqui referido designa uma "operação pela qual o indivíduo expulsa de si e localiza no outro, pessoa ou coisa, qualidades, sentimentos, desejos e mesmo 'objetos', que ele desdenha ou recusa em si" (Laplanche e Pontalis, 1986, p. 478). 
É impossível fugir ao fato de que o verdadeiro fator determinante é, invariavelmente, a hostilidade inconsciente. Uma corrente hostil de sentimento como esta contra os parentes mais chegados e queridos de uma pessoa pode permanecer latente durante toda a vida, ou seja, sua existência pode não ser revelada à consciência, diretamente, ou através de algum substituto. Entretanto, quando eles morrem, isso não é mais possível e o conflito torna-se agudo. (1913, p. 84-5) (grifos nossos)

Isto posto, temos que o luto seria originário de uma certa intensificação dos sentimentos afetuosos que torna insuportável a latência da hostilidade, mas que, ao mesmo tempo, não permite a satisfação pela morte em conseqüência dela. Entretanto, como o luto compreende apenas um período de tempo, o conflito que nele ocorre vai perdendo a intensidade e, assim, vai cessando a severidade do tabu sobre os mortos. Dessa maneira, podemos dizer que o luto aqui se torna condição tanto para a emergência do tabu relativo aos mortos, como para o seu esquecimento. É como se o luto constituísse também um processo que vai permitindo a diminuição da severidade das práticas tabus na mesma medida em que vai permitindo também a diminuição da intensidade dos sentimentos (tanto hostis, quanto afetuosos) dirigidos aos mortos.

Observamos que é na busca de explicação para o medo dos mortos que Freud aponta para a influência e a função psicológica dele no luto, contribuindo para que esse realize a sua "missão" de desligar psicologicamente os sobreviventes dos mortos:

O fato de os demônios serem sempre encarados como os espíritos daqueles que tinham morrido recentemente mostra, melhor que qualquer outra coisa, a influência do luto na origem da crença nos demônios. O luto tem uma missão psíquica muito específica a efetuar; sua função é desligar dos mortos as lembranças e as esperanças dos sobreviventes. (ibid., p. 87)

Transformados em demônios, os mortos são temidos pelos sobreviventes, que, em conseqüência, lutam para se "afastar" deles (ou seja, lutam para se desligar libidinalmente). O enlutado desenvolve, então, os mecanismos necessários para a separação e desligamento dos mortos por meio da transformação deles em demônios. Neste ponto, interessa lembrar que aqui também se encontram algumas das idéias que foram desenvolvidas em "Luto e melancolia" (1917) sobre o "trabalho de luto" (trauerarbeit, em alemão) que consistiria no trabalho de elaboração intrapsíquico, consecutivo à perda de um objeto de amor, pelo qual haveria um processo de desligamento libidinal progressivo em relação ao amado perdido. De acordo com Freud, o que atesta a existência desse trabalho intrapsíquico seria a falta de interesse pelo mundo exterior que se instala com a perda do objeto e que mobilizaria toda a libido pela dor e pelas recordações, 


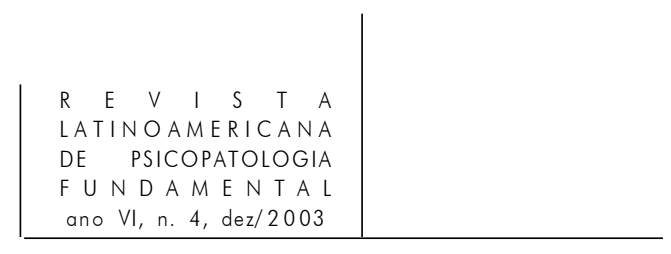

havendo uma espécie de hiperinvestimento no objeto perdido na realidade psíquica do enlutado que dá lugar, progressivamente, ao desinvestimento em relação ao objeto perdido e reinvestimento no mundo e em seus objetos.

É interessante observar também o lugar das atitudes de reverência em relação aos mortos. Quando a "missão" do luto é cumprida e sua dor diminui, e com ela o remorso e as autocensuras, diminui também o medo dos mortos e é a partir daí que tem lugar a reverência. Assim, "os mesmos espíritos que inicialmente foram temidos como demônios podem agora esperar encontrar um tratamento mais amistoso; são reverenciados como ancestrais e lhes são dirigidos apelos em busca de ajuda" (Freud, 1913, p. 87).

Portanto, podemos dizer que, nessa acepção, o luto constitui um processo necessário frente à morte de outrem e que permite o desligamento dele e das influências que poderiam ter sobre os vivos, fazendo diminuir a intensidade dos sentimentos em relação aos mortos que dão origem tanto ao medo quanto à reverência a eles.

A reverência parece ter lugar quando não se faz mais necessária a expressão dos sentimentos hostis - anteriormente transformados (projetados) - que serviram como recursos para que a missão do luto tivesse sucesso. Por outro lado, na reverência aos mortos existe um outro componente importante: o temor. ${ }^{3}$ 34 Suspeitamos que o medo dos mortos - resultado, como vimos, da hostilidade a eles dirigida - persistiria como garantia da manutenção do sucesso do luto. Ao temer os mortos, os enlutados podem mantê-los afastados. Seguindo esse raciocínio, poderíamos inferir que a expressão dos sentimentos hostis constitui algo próprio e necessário às relações humanas em situações de perda e que se faz valer sob a forma de mecanismos eficazes para que o luto se processe de modo saudável.

Perguntamo-nos, agora, sobre como poderíamos entender a forma como essa questão se processava nos tempos contemporâneos a Freud e também em nossos dias atuais. Acompanhando as idéias de Freud, teríamos que o processo de civilização operou uma mudança na relação entre os sobreviventes e os mortos através do tempo; uma mudança na qual houve "uma extraordinária diminuição da ambivalência" e que, conseqüentemente, redimensiona a questão da hostilidade:

Agora é bastante fácil dominar a hostilidade inconsciente contra os mortos (embora sua existência ainda possa ser reconhecida), sem qualquer dispêndio específico de energia psíquica. Onde, em tempos anteriores, o ódio satisfeito e a afeição sentida lutavam um contra a outra, encontramos agora uma espécie de

3. Note-se aqui que o medo dos mortos assume duas designações diferentes: o "terror" em relação aos demônios e fantasmas e o "temor" aos deuses. 


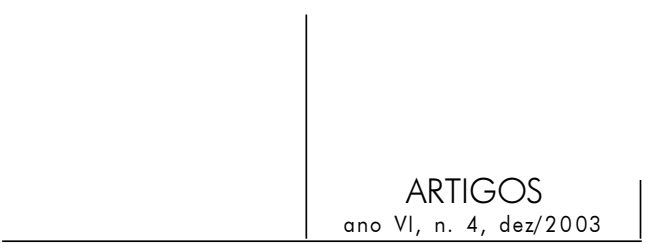

cicatriz que se formou sob o modelo da piedade, a qual declara: de mortuis nil nisi bonum. Somente nos neuróticos o luto pela perda dos que lhes eram caros é ainda perturbado por autocensuras obsessivas, cujo segredo é revelado pela psicanálise como sendo a velha ambivalência emocional. (ibid., p. 88) (grifos $\operatorname{nos} \operatorname{sos})^{4}$

Tais idéias nos sugerem que a ambivalência revelada no luto, tal como vivido pelos povos civilizados, vai perdendo lugar em termos de intensidade, ou seja, a transformação que se opera em relação à ambivalência é quantitativa (econômica). Continua a existir o conflito de sentimentos como uma característica da relação entre os vivos e os mortos, sendo que de maneira menos intensa. Quando o conflito é intensificado, vemo-nos diante da neurose. Em outras palavras, de componente característico do luto nos povos ditos primitivos, a ambivalência afetiva intensa, talvez sob a força do processo de desenvolvimento da civilização, torna-se, progressivamente, componente patológico do luto em neuróticos. Tal mudança na intensidade da ambivalência traz consigo, segundo Freud, o desaparecimento das práticas tabu que são entendidas explicitamente como sintomas da ambivalência afetiva e solução para o conflito dela resultante:

Não precisamos discutir aqui como foi que esta alteração ocorreu, que parte dela é devida a uma modificação constitucional e qual a parte que se deve a uma melhoria real nas relações familiares. (...) É de se supor que como essa ambivalência diminuiu, o tabu (sintoma da ambivalência e um acordo entre os dois impulsos conflitantes) lentamente desapareceu. Dos neuróticos, que são obrigados a reproduzir o conflito e o tabu dela resultante, pode-se dizer que herdaram uma constituição arcaica como vestígio atavístico; a necessidade de compensar isso, por força da civilização, é que os leva a um imenso dispêndio de energia mental. (ibid., p. 87-8)

Notemos aqui apenas uma certa idéia de evolução das relações de uma constituição dita "arcaica" para uma dita "civilizada" a partir da "diminuição" da ambivalência. Entretanto, parece-nos que essa idéia não representa propriamente, como se poderia pensar, uma defesa freudiana das relações ditas civilizadas. Isso porque é claramente apresentada a observação sobre o dispêndio de energia

4. Este "modelo de piedade" é também considerado por Freud em "Reflexões para os tempos de guerra e de morte" (1915), estudo - que merece ser notado - sobre as atitudes humanas diante da morte e dos mortos, na qual escreve: "Para com a pessoa que morreu, adotamos uma atitude especial - algo próximo da admiração por alguém que realizou uma tarefa muito difícil. Deixamos de criticá-la, negligenciamos suas possíveis más ações, declaramos 'de mortuis nil nisi bonum' (...)". (p. 96) 


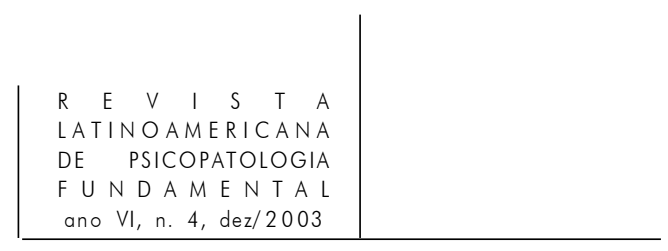

necessário para compensar a não-reprodução do conflito ambivalente e do tabu dele resultante. Junto com as transformações operadas pelo desenvolvimento da civilização, vem um maior esforço e dispêndio de energia para que as relações entre sobreviventes e mortos, antes mediadas pelas práticas tabus, conduzam ao "sucesso do luto".

Diante dessas considerações, parece-nos possível fazer uma certa analogia entre o processo de desenvolvimento da civilização e o próprio trabalho de luto na medida em que, em ambos, há uma progressiva diminuição da intensidade dos sentimentos, tanto afetuosos, como hostis, sob a égide de certas restrições, proibições e observâncias que caracterizam os costumes e manifestações da cultura. Entretanto, como podemos depreender das elaborações freudianas, enquanto o processo de desenvolvimento da civilização deu origem, em certo sentido, às neuroses, o trabalho de luto bem-sucedido faz com que o sobrevivente "retorne à vida", no sentido de restabelecer as suas atividades e interesses no mundo.

É pertinente observar ainda como as mudanças empreendidas pelo desenvolvimento da civilização nas relações entre sobreviventes e mortos, para as quais Freud aponta, são entendidas em termos da quantidade ou intensidade da ambivalência. Essa parece ser a ênfase freudiana. Entretanto, lembramos que essas transformações resultam nas mudanças da própria qualidade das práticas tabu que vão progressivamente desaparecendo e dando lugar a outros costumes e práticas em relação aos mortos que configuram manifestações de luto.

\section{Considerações finais}

Diante da análise que empreendemos, observamos que o luto não se revela apenas, como se poderia pensar, na intimidade da realidade psíquica do enlutado. Nesse sentido é que ao analisar as idéias relacionadas ao luto presentes em "Totem e tabu" (1913), construímos um cenário de idéias no qual pudemos dar forma a uma certa compreensão do luto enquanto elemento importante da relação do ser humano com os mortos e com a morte em si. Contudo, essa forma foi dada respeitando os limites das construções que, por um lado, acompanham uma visão histórica das relações humanas e, por outro, transcendem as especificidades de contextos culturais diversos, utilizando certos contextos como exemplos para uma visão mais ampla. Pensamos que, talvez, essa seja uma opção necessária ao autor que busca também, na raiz da civilização, os outros indicadores para a compreensão do adoecer neurótico. Parece-nos que o próprio modo de teorizar de Freud nos remete, quase inevitavelmente, a uma certa compreensão das 


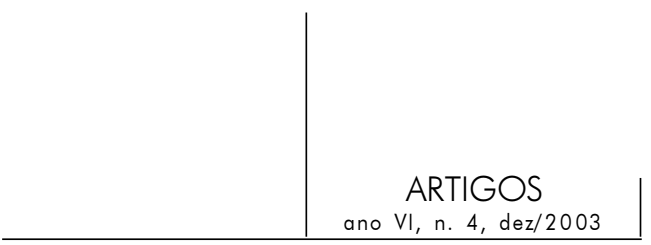

neuroses como ponto de partida para uma compreensão dos aspectos históricos, sociais e culturais que envolvem o tema. Isso porque a ênfase recai sobre a compreensão da natureza da relação entre as diferentes formas de neurose e instituições culturais e na percepção de como um estudo da psicologia das neuroses é importante para a compreensão do desenvolvimento da civilização e da cultura e vice-versa.

$\mathrm{O}$ que as elaborações freudianas nos sugerem e nos autorizam a supor é que o luto, como fenômeno humano, pode ser concebido também como uma manifestação cultural, ritualizada sob muitos aspectos e cujo sentido e atuação é socialmente compartilhado. Isso não quer dizer que estamos propondo duas acepções freudianas de luto completamente independentes uma da outra e que dariam conta da experiência humana de sofrimento na esfera psíquica e na esfera cultural isoladamente. Não queremos dizer que, por um lado, há o luto enquanto um afeto e um trabalho psicológico e, por outro, de modo inteiramente independente, o luto como uma manifestação cultural.

O luto, em nosso entender, assume no pensamento freudiano o estatuto de fenômeno psicológico e cultural e se insere como um elemento importante para o entendimento das relações e das atitudes humanas diante da morte. Assim sendo, o trabalho de luto supõe uma espécie de integração entre a realidade material e sociocultural, que envolve a morte do objeto, e a realidade psíquica em que o objeto sobrevive. Essa integração vai operar transformações, tanto no universo intrapsíquico do enlutado, no qual vai havendo o progressivo reconhecimento da morte do objeto, como no seu universo social, no qual vai havendo uma progressiva reorganização de modo a garantir um novo lugar para o morto e a permitir que novas relações de amor sejam construídas. Temos, assim, que a concepção freudiana de luto não se encontra desvinculada da inserção do enlutado no mundo social que exige do sujeito o reconhecimento da perda e a manutenção da vida.

\section{Referências}

Freud, S. (1913). Totem e tabu. In: Edição Standard Brasileira das Obras Psicológicas Completas de Sigmund Freud - ESB. Rio de Janeiro: Imago, 1996. v. XIII. (1915). Reflexões para os tempos de guerra e morte. In: ESB, op. cit. v. XIV. (1916). Sobre a transitoriedade. In: ESB, op. cit. v. XIV. (1917). Luto e melancolia. In: ESB, op. cit. v. XIV. (1930). Mal-estar na civilização. In: ESB, op. cit. v. XXI. (1930). Malestar en la cultura. In: Obras Completas. Madrid: Biblioteca Nueva, 1981. v. III. 


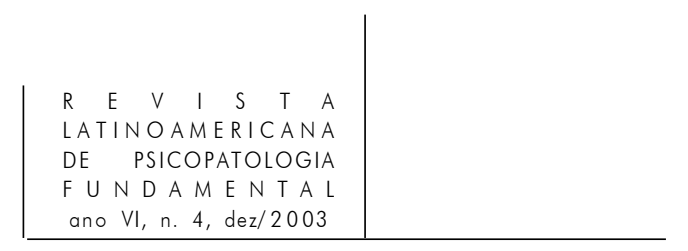

Fustel De Coulanges, N. D. A cidade antiga. São Paulo: Martins Fontes, 1998.

Laplanche, J. e Pontalis, J-B. (1967). Vocabulário de Psicanálise. São Paulo: Martins Fontes, 1986.

SAFra, G. A face estética do self: teoria e clínica. São Paulo: Unimarco, 1999.

\section{Resumo}

Este artículo aborda el tema de la experiencia de sufrimiento en el duelo, tomando como referencia algunas de las construcciones teóricas de Sigmund Freud. Se propone indagar las elaboraciones freudianas que conciben el duelo como fenómeno psicológico que participa de las tradiciones tabúes, caracterizándolas y reflejando actitudes humanas frente a la muerte. El análisis de tales tradiciones permite considerar que la ambivalencia afectiva participa de la experiencia de sufrimiento individual y de las manifestaciones de duelo culturalmente compartidas de tal modo que contribuye para la realización del "trabajo de duelo" en las dimensiones intra-psíquica y cultural.

Palabras claves: Duelo, tabú, ambivalencia afectiva, cultura

Cet article aborde le thème de l'expérience de la souffrance dans le deuil, en prenant comme référence quelques unes des constructions théoriques de Sigmund Freud. Il propose d'investiguer les élaborations freudiennes qui conçoivent le deuil comme un phénomène psychologique faisant partie des traditions taboues, en les caractérisant comme des attitudes humaines face à la mort. L'analyse de telles traditions taboues permet de considérer que l'ambivalence affective fait partie de l'expérience de souffrance individuelle et des manifestations culturellement partagées du deuil, de façon à contribuer à la réalisation du "travail de deuil" dans les dimensions intrapsychique et culturelle.

Mots clés: Deuil, tabou, ambivalence affective, culture

This article deals with the suffering experienced in mourning, based on theoretical Freudian constructs. Freudian positions on mourning as a psychological phenomenon related to traditions of taboos are discussed, as well as human attitudes in the face of death. An analysis of these traditions allows one to see that there is affective ambivalence in the individual experience of suffering and in the culturally shared manifestations of mourning in a way that contributes to "grief work" on the cultural and intrapsychical levels.

Key words: Mourning, grief, taboo, affective ambivalence, culture

Versão inicial recebida em janeiro de 2003

Aprovado para publicação em novembro de 2003 